\title{
Financial Management of Small Organizations Based on a Cognitive Approach
}

\author{
N. Morozko ${ }^{1}$, N. Morozko², V. Didenko ${ }^{3}$
}

\begin{abstract}
:
In most cases small business organizations insufficiently justify economic calculations for the formation of financial resources, which adversely affects their sustainable development.

Under the current circumstances, the need for sound financial management increases, which ensures a stable financial status of the organization and the prospects for increasing its value.
\end{abstract}

The aim of this paper is to identify the conditions for the dynamic financial management of small organizations based on a cognitive approach.

The proposed cognitive model allows establishing the mechanism of mutual influential factors of internal and external environment on the effective use of financial resources.

Using the proposed model, it is possible to forecast changes in financial results.

Keywords: Management, small organizations, financing, cognitive modeling.

\footnotetext{
${ }^{1}$ Corresponding author, Finance University under the Government of the Russian Federation, Moscow, Russia, e-mail: natmorozko@mail.ru

${ }^{2}$ Finance University under the Government of the Russian Federation, Moscow, Russia, email: ninamorozko@list.ru

${ }^{3}$ Finance University under the Government of the Russian Federation, Moscow, Russia, email: didenkovu@gmail.com
} 


\section{Introduction}

Cognitive modeling is a demanded research tool in an unstable and weakly structured environment, to which small business belongs. Cognitive modeling makes it possible to identify the problems existing in the environment, uncovering contradictions and analyzing the processes that are taking place. To ensure competitive advantages on the market, small organizations are forced to apply modern methods in managing financial resources. There are existing recipes for optimizing financing sources. Each organization has different objectives in attracting financial resources. An evolution study on the justification of activities' financing within small organizations showed that, during the present stage, such problems have not been completely resolved.

The company's business model (Henrikki et al., 2005) is viewed as a cognitive system through which managers influence processes. Similar studies were conducted in the work of Se'rgio Cavalcante et al. (2011) on the dynamics of the business model, the degree of innovation and the identification of missing links. Other author (Glykas, 2012) considers the use of fuzzy cognitive maps (FCM) in strategic maps (SMs).

Also, paper by Wilkinson et al. (2013) describes how the practice of likelihood scenarios is confronted with the complexity of assessing and solving the problems of the 21st century. The study of socially responsible investment has been undertaken (Glac, 2009) from the position of influence of decisions and options for deviating investment. In further studies (Narayanan et al., 2011), an analysis of the development of cognitive forecasting in strategy was conducted.

Some authors (Colin and Ackermann, 2002) examine expert opinions on cognitive mapping for policy analysis in the public sector. For small and medium-sized businesses, one of many studies by Osiyevskyy et al. (2015) examines the results of integrated business planning. Low use of bankruptcy methods and procedures negatively affects the finances of companies (Gurrea-Martínez and Aurelio, 2016).

Prospects and limitations of small business are explored in several countries (Rahman et al., 2010; Carstina et al., 2015; Gubin et al., 2017). Many authors note that different approaches to the selection of sources of financing are used, but there is no mechanism for sound financing management that positively influences performance indicators.

Terms, sizes, types of attracting financial flows of small organizations depend on various factors, among which the most significant are: the type of economic activity of the organization; features of the assets used; credit history; cost of borrowed capital; level of demand for goods or services produced; profitability of used assets and others. 


\section{Methodology}

When choosing the sources of financing, one should focus not on intuition, but on the basic prerequisites for choosing a source, with the disclosure of the basic concept associated with the problems of optimization of sources of financing, with a vector for the target capital structure of the firm within the available funding sources. The cognitive approach is a modern technology of system's analysis. The essence of cognitive modeling is expressed in the interpretation of problems and development trends under the shape of a model in which various scenarios of situations and the direction of their change are considered. The validity of management decisions in rapidly changing conditions increases with the use of cognitive models. With the application of the cognitive approach, the terms for the development of the organization's development strategy are reduced, and the validity is increased considering the influence of external and internal factors.

Cognitive structuring allows identifying target and problematic issues in the organization's activities, monitoring the most significant factors, establishing causal relationships between these factors. Cognitive analysis is conducted considering the stipulated tasks in several stages. The main goal of cognitive analysis is achieved by the consistent solution of certain tasks. The main stages of cognitive analysis are:

1. Substantiation of the purpose and objectives of the research;

2. Collection and analysis of statistical information on the object of management, considering external influences;

3. Determination of significant factors affecting the change in conditions;

4. Construction of a cognitive map that allows you to establish the cause-effect relationship between the factors;

5. Determination of the degree of mutual influence of factors based on a mathematical model;

6. Identify, based on the cognitive model, possible options for the development of conditions determine the direction of development to achieve the set goals.

The purpose of this study is to identify the conditions for the dynamic management of the financing of small organizations based on a cognitive approach. The objectives of the study are: to identify factors that affect the effective functioning, the definition of cause and effect relationships, the construction of a cognitive map, the definition of the aggregate of managing factors of financing a small organization. The selection of the main factors is based on SWOT analysis (Table 1):

Table 1. Matrix of SWOT-analysis of the activity of a small organization

\begin{tabular}{|l|l|l|}
\hline \multicolumn{1}{|c|}{ S - strengths } & \multicolumn{1}{c|}{ W - weaknesses } \\
\cline { 2 - 3 } & \multicolumn{1}{|c|}{ A small start-up capital } & Shortage of financial resources \\
\cline { 2 - 3 } & Greater turnover of funds & Low level of property status \\
\cline { 2 - 3 } & Flexibility, rapid adaptation to & Lack of funding sources \\
\hline
\end{tabular}




\begin{tabular}{|l|l|l|}
\hline \multirow{4}{*}{$\begin{array}{l}\text { Internal } \\
\text { factors }\end{array}$} & change & \\
\cline { 2 - 3 } & Unity of the owner and manager & Unstable structure of capital \\
\cline { 2 - 3 } & Simplified organizational structure & $\begin{array}{l}\text { Inadequate supply of own circulating } \\
\text { assets }\end{array}$ \\
\hline \multirow{3}{*}{$\begin{array}{l}\text { External } \\
\text { factors }\end{array}$} & O - opportunities & T- threats \\
\cline { 2 - 3 } & Growth to the level of big business & The economic situation in the country \\
\cline { 2 - 3 } & Creative self-realization & High level of competition \\
\cline { 2 - 3 } & A strong niche in the local market & Limited demand for products \\
\cline { 2 - 3 } & Possibility of obtaining state support & Significant tax burden \\
\hline
\end{tabular}

Based on the analysis of various possible combinations of strengths and weaknesses with threats and opportunities (SWOT analysis), the problem field of the small organizations being researched is formed: a lack of financial resources, a low level of financial stability, insufficient provision of own working capital, significant tax burden, conditions for obtaining state support.

The study of various factors is based on the collection, systematization, analysis of existing statistical information on the indicators of small business organizations of the Russian Federation. According to the latest data, the share of small business in the country's GDP is about 1/5, which indicates great opportunities for further growth. At present, according to the Federal Law № 209-FZ of July 24, 2007 "On the Development of Small and Medium-Sized Enterprises" and Government Decree No. 265 of 04.04.2016, to small business organizations includes business associations, partnerships, production and consumer associations, as well as individual entrepreneurs with a number of employees from 16 to 100 people. The maximum annual amount of income received from carrying out entrepreneurial activities cannot exceed 800 million rubles".

Investigation and characterization of factors and indicators of capital structure were carried out using the method of correlation-regression analysis. The definition of dependent and independent variables within the framework of this method on the sample of small business subjects made it possible to identify the determinants that affect the formation of the capital structure of economic entities. The degree of influence of individual factors on the level of performance of small organizations is determined based on the developed model:

ROA $=0,23+0,08 \mathrm{CR}-0,006 \mathrm{RPR}-0,19 \mathrm{FL}+0,07 \mathrm{E} / \mathrm{A}+0,02 \mathrm{RTR}-0,004 \mathrm{PTR}-0,11$ $\mathrm{T}+1,71 \mathrm{RSS}$

ROA - return on assets;

CR - solvency (current ratio);

RPR - the ratio of payables and receivables;

$\mathrm{FL}$ - debt-to equity ratio;

E/A - financial stability (equity - to- assets ratio);

RTR - receivables turnover ratio; 
PTR -payables turnover ratio;

$\mathrm{T}$ - tax burden;

RSS - level of state support to small organizations.

Preliminary analysis of the obtained values allowed to ensure the reliability of the included data, sharply deviating indicators were excluded from the considered population. The proposed model allows us to describe the process of mutual influence of factors of the internal and external environment on the effectiveness of the use of aggregate capital, consider changes (variations) in the parameters of this environment. Interpretation of the proposed model allows us to conclude that the provision of financial resources for small businesses depends on a certain set of complex parameters. Each of the parameters included in the model characterizes the interactions of various factors that determine the intensity of the organization's financial flows. Based on the analysis of Russian and foreign methods, expert surveys, it is necessary to justify the recommended values of the coefficients included in the model. A certain guideline in the development of standards for the coefficients included in the integral model are the following: to adjust, where possible foreign standards based on the Russian specifics, business activity of this type of organization; to apply the resulting average values for the group of values of the coefficients.

The proposed system of indicators is based on the public reporting data of organizations. This condition makes the appraisal affordable, which allows you to monitor changes in the financial status of the organization by all participants in the economic process. It also makes it possible to assess the effectiveness and objectivity of the proposed integrated assessment methodology. Determining the relationship between factors by examining the cause-effect chains is done based on the cognitive map (Figure 1).

The degree of influence of each factor on the score in the developed model is both positive and negative. In the figure above, it can be seen that, while other factors are equal, the return on capital increases with increasing E/A - financial stability (0.07); increase in RTR - receivables turnover $(0,02)$ and increase in the RSS - share of state support; At the same time, the profitability of capital increases with a decrease in FL - the share of borrowed funds (0.19), with a decrease in $\mathrm{T}$ - the tax burden (0.11).

Thus, financial management makes it possible to consider the multi-factority and alternatives of financial management in order to achieve the goals and objectives. In the absence of a purposeful approach, the activities of business entities become unreasonable and chaotic. As a result, the business entity is in great dependence with random situations. Therefore, financial management is an indispensable element of management, characterizes the ability to systematically identify deviations and, on this basis, make appropriate decisions. Ignoring the sound management of financing leads to a loss of the presentation of financial management objectives, to inadequate choice of forms, methods, means and mechanisms of financial management. Such 
processes are accompanied by a loss of dynamism and, at the same time, stability in the work of small organizations.

Figure 1. Cognitive framework for analyzing financing problems

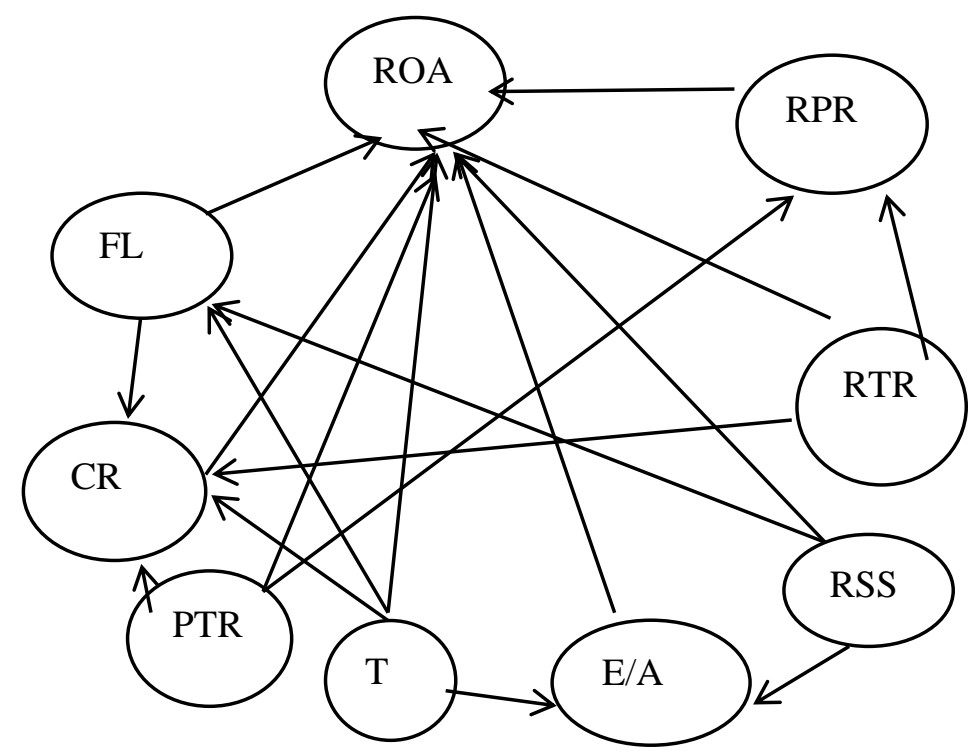

\section{Result and Discussion}

Cognitive modeling with the help of situational analysis makes it possible to develop alternative solutions for financing and, accordingly, improving the performance of small business organizations. With the help of cognitive modeling:

- analysis of ways and cycles of the cognitive map, which makes it possible to analyze the cause-effect relationships between the factors affecting the efficiency of financing small organizations;

- analysis of the conditions for the sustainability of the functioning of small organizations;

- identification of possible changes in the financing of small organizations.

The developed cognitive approach differs from existing methods: first, by the alternative, since the analysis of the model makes it possible to influence the most acceptable factors under the prevailing conditions; second, the objectively conditioned nature of the factors. This situation is explained by the fact that, unlike most other methods, cognitive models are based on regularities, revealed based on real financial indicators of the organizations in question. Within the framework of the new management paradigm, a cognitive approach to the management of 
financial resources with a focus on established goals is needed, that is, the choice of a specific model for use in practice.

The study of such dependencies is of great importance for assessing the influence of various factors on the performance indicators of the business entity. According to this model, the level of return on capital determines the al- tentativeness of finding the directions of its increase. Each of the initial indicators is decomposed into a factor system with varying degrees of detail, which determines the boundaries for identifying and assessing financial reserves. The study of procedural limitations and application of the mathematical apparatus made it possible to conclude that the methods of system analysis can be used to identify stochastic dependencies in the examination of models of economic systems for managing financial resources of small business subjects. Cognitive analysis of the obtained modeling results allowed to give a qualitative description of the obtained results:

- economic entities that show high and moderate profitability indicators prefer internal sources of financing economic activities to external sources. An increase in profitability also leads to a reduction in the use of debt financing resources; - the tendency to increase the share of both long-term and short-term liabilities is weakly correlated with potential tax preferences. At the same time, for a number of economic entities, the increase in long-term sources of financing has a clear relationship with the prospect of using the "tax shield" effect; - there is a direct relationship between the level of the debt burden and the variable that characterizes the growth rate of the organization. The growth is higher with lower debt load indicators;

- In general, the formation of the capital structure and the choice of sources of its financing have a significant effect on the traditional determinants, such as: profitability, financial risk, taxation, as well as growth rates, size and structure of assets;

- the resulting set of determinants affecting the current structure of capital financing is different.

When deciding on borrowing, small businesses should consider financial stability indicators; return on equity; potential for attracting investments.

\section{Conclusion}

The identification of problem factors based on the cognitive approach allows us to conclude that limited access to financial resources reduces the motivation to grow the market value of the business. The current state contradicts the goal of managing the capital structure - maximizing the company's market value based on optimizing the risk-return ratio of borrowing. The policy of using different sources of funding should be an adequate response policy - reducing the cost of raising funds. 
The lack of own financial resources of small business organizations makes it necessary to attract borrowed funds. The accumulation of debt in relation to assets or revenues, that is, the growth of financial leverage, can positively affect the efficiency of the business functioning to a certain level. Rational capital structure assumes such a ratio between own and borrowed capital, which provides an optimal combination of risk and return and, therefore, maximizes the cost of business. The proposed cognitive approach makes it possible to investigate the dynamics of sources of financing for small organizations, and to forecast changes in financial results. The cognitive model makes it possible to justify developing the tactics and strategy of small organizations to ensure financial sustainability

\section{References:}

Axelrod, R. 1976. The Structure of Decision: Cognitive Maps of Political Elites. Princeton University Press.

Bodi, Z., Kane, A., Marcus, A.J. 2002. Principles of investment M., Williams, 982.

Brealey, R., Mayer, S. 2012. Principles of Corporate Finance, 2nd ed., Moscow, ZAO Olympus-Business, 1120.

Carstina, S., Siminica, M., Circiumaru, D. and Tanasie, A. 2015. Correlation Analysis of the Indicators of Asset Management and Profitability. International Journal of Economics \& Business Administration, 3(2), 3-21.

Chytas, P., Glykas, M., Valiris, G. 2010. Software reliability modelling using fuzzy cognitive maps. Studies in Fuzziness and Soft Computing, 217-230.

Copeland, T., Koller, T., Murrin, J. 2008. Valuation Measuring and managing the value of companies. M., Olimp-Business, 576.

Damodaran, A. 2008. Investment valuation. Tools and techniques for valuing any assets. Moscow. Alpina Business Books, 1342.

Dickerson, J.A., Kosko, B. 1997. Virtual worlds as fuzzy cognitive maps. Fuzzy engineering, 125-141, Upper Saddle River, NJ., Prentice Hall.

Diffenbach, J. 1982. Influence diagrams for complex strategic issues. Strategic Management Journal, 3, 133-146.

Eden, C. 1998. Cognitive mapping. European Journal of Operational Research, 36, 1-13.

Gubin, P.N., Litvinova, A.S. and Arsenyeva, A.V. 2017. Types of Financial and Credit Products: Concept, Subject, and Place on Russian and Global Financial Market. European Research Studies Journal, 20(3B), 524-529.

Gurrea-Martínez, A. 2016. The Low Use of Bankruptcy Procedures in Spain: Reasons and Implications for the Spanish Economy. Ibero-American Institute for Law and Finance, Working Paper Series 5.

Georgopoulos, V., Malandraki, G., Stylios, C. 2002. A fuzzy cognitive map approach to differential diagnosis of specific language impairment. Journal of Artificial Intelligence in Medicine, 679, 1-18.

Ghoshal, D.M. 2005. Bad management theories are destroying good management practices. Academy of Learning and Education, 4, 75-91.

Glykas, M. 2010. Fuzzy cognitive maps: Advances in theory, methodologies, tools and applications. Studies in Fuzziness and Soft Computing, 23.

Higgins, R.C. 2007. Financial analysis: tools for making business decisions. M., ID Williams, 464.

Hong, T., Han, I. 2002. Knowledge based data mining of news information of the internet 
using cognitive maps and neural networks. Journal of Expert Systems with Applications, 23(1), 1-8.

Jensen, M.C. 2002. Value maximization, stakeholder theory, and the corporate objective function. Business Ethics Quarterly, 12, 235-247.

Kaplan, R.S., Norton, D.P. 1996. Using the balanced scorecard as a strategic management system. In Harvard Business Review, January/February, 75-85.

Kosko, B. 1986. Fuzzy cognitive maps. International Journal of Man-Machine Studies, 1, 65-75.

Langbert, M., Friedman, H. 2002. Continuous improvement in the history of human resource management. Journal of Management Decision, 40(8), 782-787.

Lee, K.C., Kwon, O.B. 1998. A strategic planning simulation based on cognitive map knowledge and differential game. Journal of Simulation, 7(5), 316-327.

Lindgren, M., Bandhold, H. 2009. Scenario Planning: The Link between Future and Strategy Palgrave Macmillan, 216.

Liu, Z.Q. 2000. Fuzzy cognitive maps: Analysis and extension. Tokyo, Springer.

Myers, S., Majluf, N. 1984. Corporate Financing and Investment Decisions When Firms Have Information That Investors Do Not Have. Journal of Financial Economics, 13(2), 187- 222.

Michael, G. 2010. Fuzzy cognitive maps: Advances in theory, methodologies, tools and applications. Berlin, Springer.

Modigliani, F. 1958. The Cost of Capital, Corporation Finance and the Theory of Investment. American Economic Review, 48, 261-297.

Osterwalder, A., Pine, Y. 2012. Construction of business models: handbook of strategist and innovator. M., Alpina Publisher, 288.

Osiyevskyy, O., Costa, S., Madill, C.M. 2015. Business Sense or Subjective Satisfaction? Exploring the Outcomes of Business Planning Comprehensiveness in Small and Medium Business Context. International Journal of Entrepreneurship and Innovation,

Othman, R. 2007. Enhancing the effectiveness of the balanced scorecard with scenario planning. International Journal of Productivity and Performance Management, 57, 259266. 